\title{
EFFECT OF COMPOSITIONS TITANIUM NITRIDE IN COPPER-BASED SINTERED ELECTRODE DURING ELECTRICAL DISCHARGE MACHINING OF TUNGSTEN CARBIDE
}

\author{
RATTIKORN SAODAEN ${ }^{1}$, APICHARTRODCHANAROWAN ${ }^{2 *} \&$ PICHAIJANMANEE $^{3}$ \\ ${ }^{I}$ Graduate Student, Department of Material Engineering, Kasetsart University, Bangkok Thailand \\ ${ }^{2}$ Associate Professor, Department of Material Engineering, Kasetsart University, Bangkok Thailand \\ ${ }^{3}$ Assistant Professor, Department of Mechanical and Industrial Engineering, Rajamangala \\ University of Technology Krungthep, Bangkok Thailand
}

\begin{abstract}
This research studies the effect of compositions Titanium Nitride (TiN) element in copper-base electrode powder sintered during electrical discharge machining process on tungsten carbide(WC-Co). The impact study of Material Removal Rate $(M R R)$, Electrode Wear Ratio (EWR) and surface roughness $(\mathrm{Ra})$. In the experimental variables, include that current, voltage, on-time and off-time, respectively. Analyze the distribution of element using technique AFM and laser optical imaging techniques. The results showed that surface quality of workpieces and electrodes formed after spark, electrode material Cu80\%, Ni3\%, TiN17\% yielded the highest MRR $0.0038 \mathrm{~mm}^{3} / \mathrm{min}$, EWR lowest at $113.33 \%$ and surface roughness is $1.183 \mu \mathrm{m}$. Moreover, experiment was found that the effectiveness of the process is evaluated by Scanning Electron Microscopy (SEM). However, TiN composition with copper-based approximate due to high melting pointare influencing preferably improvement of MRR increase and reduce EWR.
\end{abstract}

KEYWORDS: Titanium Nitride(TiN), Compositions, EDM, Tungsten Carbide \& Surface Roughness

Received: Mar 03, 2020; Accepted: Mar 23, 2020; Published: May 04, 2020; Paper Id.: IJMPERDJUN202028

\section{INTRODUCTION}

Tungsten carbide (WC-Co)is the important material, so it is widely used to produce mold in industry since it has high hardness, high wear resistance and high melting point. With these qualities, it is suitable to apply to mold area [1-2]. However, because of its qualities, it cannot be deformed with mechanical machining methods. Thus, Electrical Discharge Machine or EDM is widely used [2-4]. The problem of machining with EDM happens because of EDM principle: releasing the electricity discharge via electrode. This is because the melting point of electrode and the workpiece are different and that results in the limited machining efficiency, which consists of workpiece material removal rate, electrode ware ratio and surface workpiece quality. Besides, it normally has a micro crack on the workpiece after EDM machining because tungsten carbide is the compound of WC and Co, which Co is the tungsten particles binder [2]. During the EDM machining process, the Co particles, which have low melting point would melt and come off before WC melting. As a result, there is a micro crack and pores over the area [3]. However, many researchers studied in area application such as $\mathrm{H}$. K. Kansal et al.[5] studied Powder Mixed Electric Discharge Machining (PMEDM), the result found that the process becomes more stable, thereby, improving the Material Removal Rate (MRR) and surface finish. S. K. Ho et al.[6] studied of powder metallurgy. 
(PM) compacted electrodes for electrical discharge surface alloying/modification of Ti-6Al-4V alloy include $\mathrm{Al}, \mathrm{Cr}$, Ti, TiC/Ni, WC/Co, Cr/Ni, Ni/Co, Ni/Mn, Ni/Fe, Ni/Si, Cu/W, Cu/Mn, Cu/Co andTiC/WC/Co and other literature relevant to this research. The experiments were found that surface modification by particle with sintering electrode and all layers were in general discontinuous, however those produced with negative polarity were more uniform, especially when using solid electrodes. Li Liet al.[7] had studied about EDM performance of TiC/copper-based sintered electrodes with could conclude a detail of this research that each material has its pros and cons on machining performance. Titanium Carbide (TiC) is an extremely hard refractory material with high melting temperature, high thermal shock and abrasion resistance [7]. It is mainly used in powder metallurgical parts including cutting tool tips, dies, wear parts, and resistant coatings. According to this problem, the researcher regarded the importance of electrode materials application which had similar quality to melting point of workpiece that helped to reduce the limitation of machining efficiency [7,11]. With this application, it studied powder metallurgy between copper-base $(\mathrm{Cu})$ and Titanium Nitride(TiN) composition in different percentage via sintering process. At present, powder metallurgy isused extensively in electrode production. Therefore, the main factor of WC-Co machining is to consider the suitable parameter for applying to electrode material [4,7]. The article applied percentage of TiN to pressed copper-base powder in order to increase the efficiency of tungsten carbide material machining and studied the quality of test workpiece surface and electrode surface with electrical discharge machining process. Result could be applied to the further work to develop the method to suit the relevant industries.

\section{EXPERIMENTAL METHODS}

\subsection{Materials and Equipments}

Experiment materials is a composite of tungsten carbide grade90WC and 10Co. The main ingredients include WC 90\%, Co $10 \%$, and other elements, which is a material that conducts electricity well, Hardness and high wear resistance and also widely employed in mold and tool applications. However, machining has a difficult done is not suitable for processing by a conventional machining process. Currently, which can be processed by the non-traditional base on EDM process. Tungsten carbide material with physical properties as shown in Table 1. The electrode materials was copper-base variation sintered with composition TiN variation level elements at TiN 17\%, TiN 12\%, TiN 9\%, TiN 7\%, and TiN 4\% and Nickel (Ni) fixed element at 3\%, respectively. The compositions are shown in Table 2. The properties of Cu-TiN electrode are shown in Table 3. The processes the powder metallurgy with hydraulics press machine with pressure $22 \mathrm{MPa}$, after process conducted sintering with an electric furnace at a temperature of 28,350 and $1100{ }^{\circ} \mathrm{C}$ respectively, due to rate increases temperatures were 5, 10 and 20 degrees celsiusper minute [7]. Moreover, machining workpiece by using turning with a diameter of $9 \mathrm{mmand}$ long $45 \mathrm{~mm}$.

Table 1: Physical Properties of Tungsten Carbide

\begin{tabular}{|l|c|}
\hline \multicolumn{1}{|c|}{ Properties } & Tungsten carbide \\
\hline Melting point $\left({ }^{\circ} \mathrm{C}\right)$ & 2,800 \\
\hline Density $\left(\mathrm{g} / \mathrm{cm}^{3}\right)$ & 15.7 \\
\hline Thermal expansion $\left({ }^{\circ} \mathrm{C}\right)$ & $5 \times 10^{-6}$ \\
\hline Electrical resistance $(\mathrm{n} \Omega \cdot \mathrm{m})$ & 52.8 \\
\hline Hardness $(\mathrm{HRA})$ & 87.4 \\
\hline Elastic modulus $(\mathrm{Gpa})$ & 648 \\
\hline
\end{tabular}


Table 2: The Compositions Ratio of Cu-TiN Electrode

\begin{tabular}{|c|c|c|c|}
\hline \multirow{2}{*}{ Electrode Type } & \multicolumn{3}{|c|}{ Composition Ratio (\%) } \\
\cline { 2 - 4 } & $\mathbf{C u}$ & $\mathbf{N i}$ & $\mathbf{T i N}$ \\
\hline 1 & 80 & 3 & 17 \\
\hline 2 & 85 & 3 & 12 \\
\hline 3 & 88 & 3 & 9 \\
\hline 4 & 90 & 3 & 7 \\
\hline 5 & 93 & 3 & 4 \\
\hline
\end{tabular}

Table 3: Properties of Cu-TiN Electrode

\begin{tabular}{|l|c|c|c|}
\hline \multicolumn{1}{|c|}{ Powder } & Cu & TiN & Ni \\
\hline Purity $(\%)$ & 99.00 & 99.90 & 99.90 \\
\hline Density $\left(\mathrm{g} / \mathrm{cm}^{3}\right)$ & 8.96 & 5.22 & 8.88 \\
\hline Melting Point $\left({ }^{\circ} \mathrm{C}\right)$ & 1083 & 2930 & 1455 \\
\hline Electric Resistivity $(\mathrm{Ohm}-\mathrm{cm})$ & $1.70 \mathrm{E}-06$ & $6.00 \mathrm{E}-03$ & $6.40 \mathrm{E}-06$ \\
\hline Thermal Conductivity $(\mathrm{W} / \mathrm{m}-\mathrm{K})$ & 385 & 19.2 & 60.7 \\
\hline
\end{tabular}

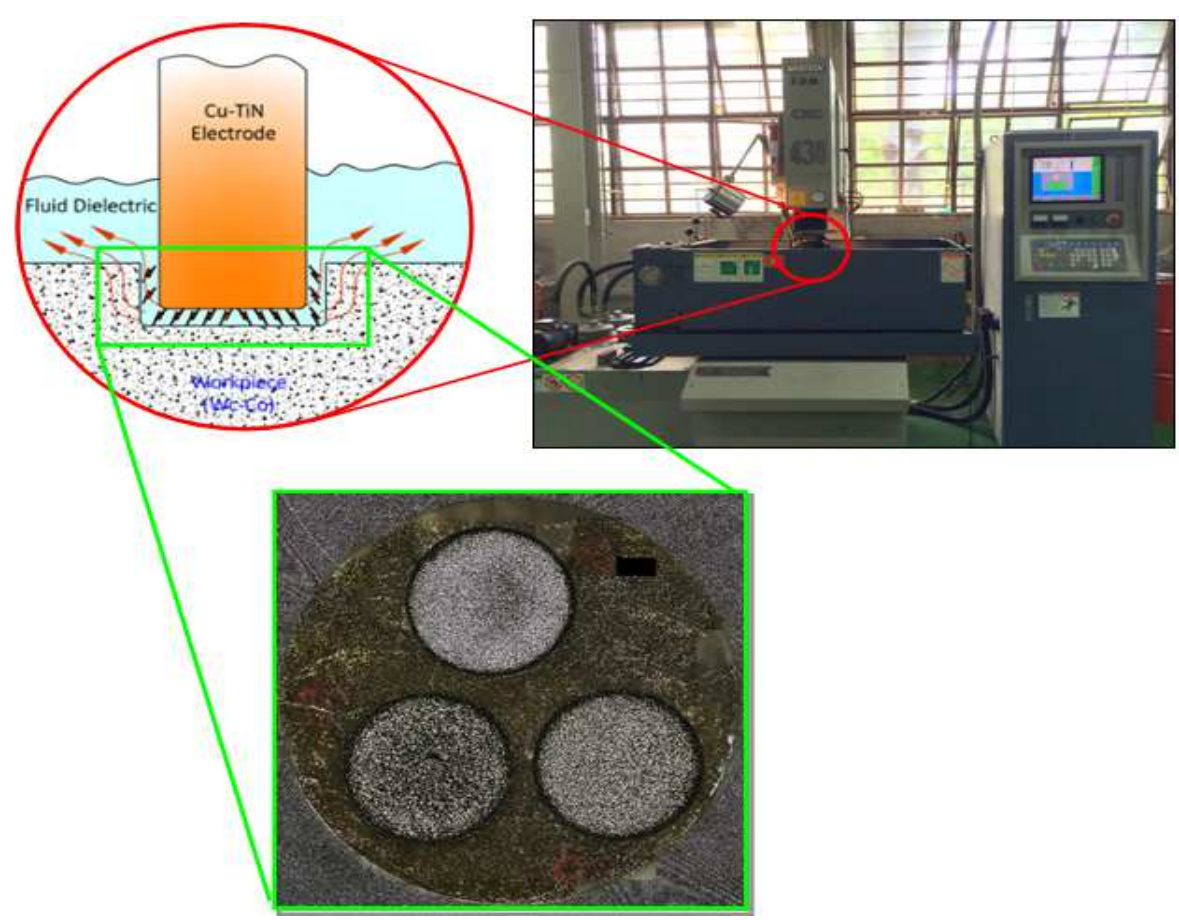

Figure 1: Illustration of Electrical Discharge Machining.

Table 4: Experiment Conditions

\begin{tabular}{|l|l|}
\hline \multicolumn{1}{|c|}{ Parameters } & \multicolumn{1}{c|}{ Details } \\
\hline Cu-TiN electrode $(\%)$ & $\begin{array}{l}\text { TiN 17\%, TiN 12\%, TiN 9\%, TiN 7\%, } \\
\text { TiN 4\% }\end{array}$ \\
\hline Diameter of electrode $(\mathrm{mm})$ & 9 \\
\hline On - time $(\mu \mathrm{s})$ & 2 \\
\hline Off - time $(\mu \mathrm{s})$ & 2 \\
\hline Polarity $(+,-)$ & $(-)$ \\
\hline Current $(\mathrm{A})$ & 3 \\
\hline Circuit voltage $(\mathrm{V})$ & 150 \\
\hline Dielectric & DielMs7000 \\
\hline Flushing & Flow rate $1.5 \mathrm{lpm}$ \\
\hline
\end{tabular}




\subsection{Experiment Procedure}

The experiment was carried out on EDM machine of computer numerical control ARISTECH EDM CNC 430 model. The material electrodes of copper-based and titanium nitride mixtures of TiN17\%, TiN 12\%, TiN9\%, TiN 7\%, and TiN 4\% were used. The condition of EDM spark was $1 \mathrm{~mm}$ of depth and $9 \mathrm{~mm}$ of diameter electrode on the material surface of tungsten carbidecomposite 90WC-10Co, diameter sized $25 \mathrm{~mm}$ and $2 \mathrm{~mm}$ of thickness. The experimental conditions are shown in Table 4. The EDM process was carried out under DielMs7000 EDM Fluid of fluid dielectric hydrocarbon. The cooling and removing of debris were done by the flushing through the $6 \mathrm{~mm}$ of diameter tube with the flow rate of $15 \mathrm{lpm}$. The duty factor was defined as the ratio of on-time discharge current to the total time of one spark cycle (on-time + off-time). The results of the experiment were assessed in terms of the Material Removal Rate: MRR. The MRR was measured from the removed amount per time unit, i.e. cubic millimeter per minute [8-9]. The electrode wear ratio:EWR was analyzed in one dimension, which was measured from the wear ratio of the electrode to the depth of the workpiece. The surface roughness was measured in terms of the arithmetic mean surface roughness: Ra against the DIN EN ISO 4288:1998 standard by using surface roughness on Mahr Pocket Surf PS1 and 3D measuring laser microscope.

The surface of the EDMed workpiece was analysed by using the Scanning Electron Microscope (SEM) and Energy Dispersive Spectrometer (EDS), respectively. Surface quality analysis of test specimen with the lowest and highest surface roughness values and check surface electrode that effect the best quality of the surface and the worst by Atomic Force Microscopy (AFM) and 3D laser microscopy for analysis of characteristic surface electrode affecting to good surface quality and bad surface quality of EDMed workpiece.

\section{RESULTS AND DISCUSSIONS}

\subsection{Material Removal Rate (MRR) and Electrode Wear Ratio (EWR)}

Results of testing the machining with EDM of each $\mathrm{Cu}$-TiN electrode ratio on tungsten carbide workpiece with different factors and conditions considering test result from MMR and EWR are shown as the graph in Figure 2. It was found that electrode $\mathrm{Cu} 80 \%$, Ni3\% and TiN17\% had the highest MRR, which was $0.0038 \mathrm{~mm}^{3} / \mathrm{min}$ and had the lowest EWR, which was $113.33 \%$ because the particles in the electrode captured and melted homogeneously. However, it depended on the appropriately $\mathrm{Cu}$ quantity to physical and mechanical quality this type of electrode. Moreover, it was the result of transferring Ni to Ti while burning in sintering process that finally resulted in porosity, density and electrode conductivity which were different based on the ratio that resulted in MRR and EWR of electrode depended on the parameter used in the experiment [10-11]. However, the low melting point of $\mathrm{Cu}$ increases the electrode wear ratio.

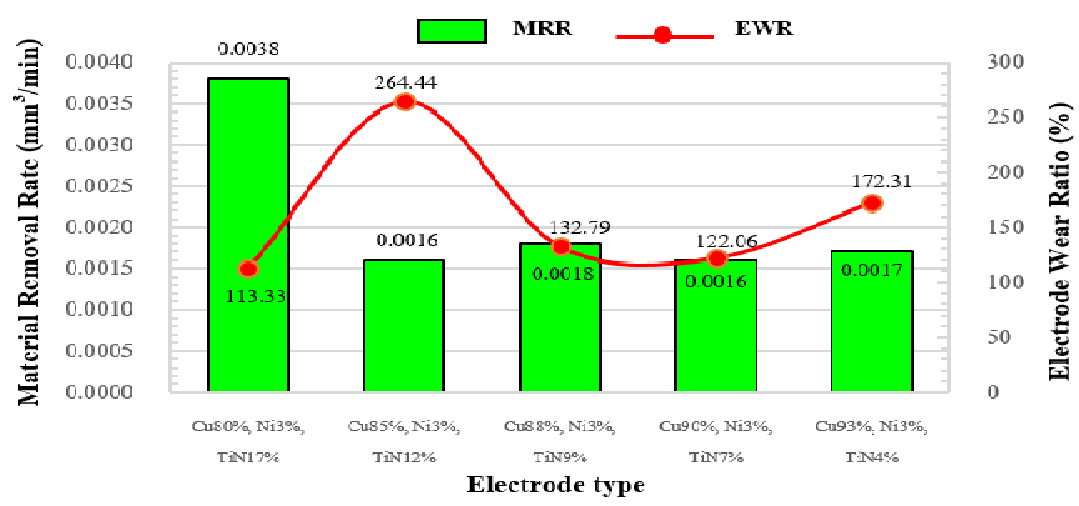

Figure 2: The Relationship Result of MRR and EWR on Electrode Composition. 


\subsection{Surface Roughness (Ra)}

Surface roughness value that occurred from the EDM spark of $\mathrm{Cu}$-TiN electrode on tungsten carbide surface of the test workpiece (Figure 3) showed the comparison of the test workpiece profiles after sparking with different electrode compounds by magnifying with surface roughness average value by surface machine tester and show the graph position from the measurement as shown in Figure 4 also show the surface roughness graph of the specimen at sparkedCu-TiN electrode in composition was found that. The lowest surface roughness value was $1.183 \mu \mathrm{m}$ when sparked with electrode $\mathrm{Cu} 80 \%, \mathrm{Ni3} \%$ and TiN17\% and the highest surface roughness value was $1.550 \mu \mathrm{m}$, when sparked with electrode Cu93\%, $\mathrm{Ni3} \%$ and TiN4\%. This was because the qualities of electrode that were appropriately to release electricity and energy accumulation while sparking made the EDM spark cycle stronger[10,14]. Moreover, the higher temperature was different depending on the compound ratio of each $\mathrm{Cu}-\mathrm{TiN}$, that is the ratio $\mathrm{Cu}$ small quantity andTiN that has a lot of element, may affect surface roughness of the test specimen to a minimum value when compared with the electrode at the rate of other ingredients. It affected the high and low average surface roughness on tungsten carbide material differently [12-13].
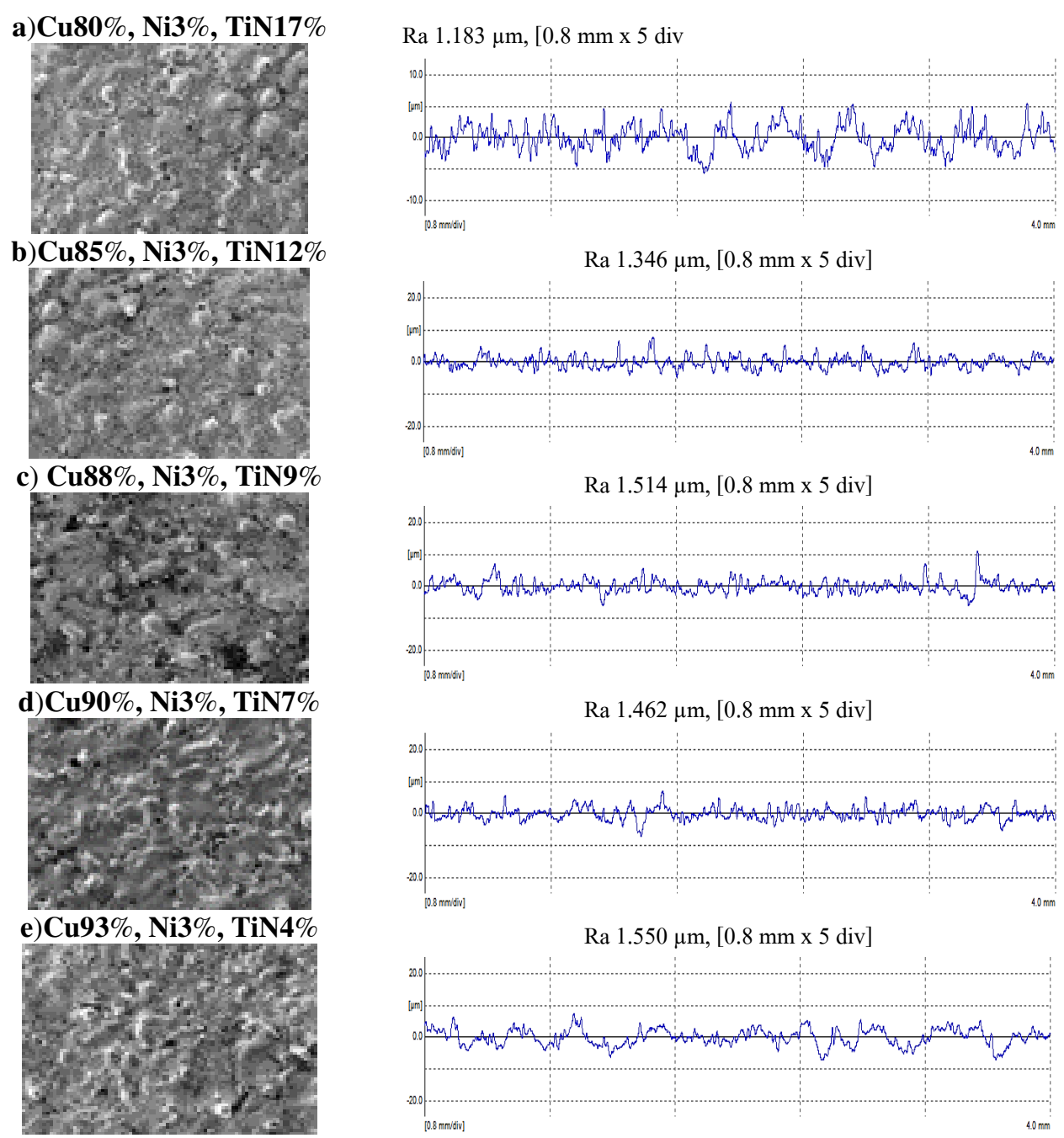

Ra $1.346 \mu \mathrm{m},[0.8 \mathrm{~mm} \times 5 \mathrm{div}]$

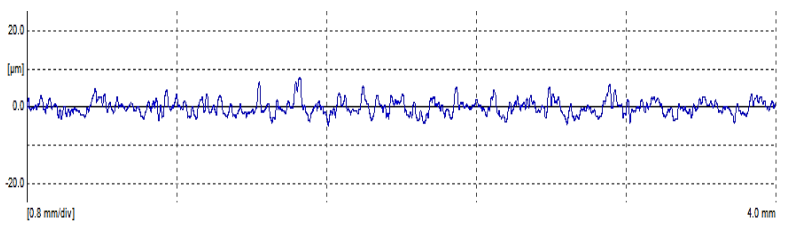

Ra $1.514 \mu \mathrm{m},[0.8 \mathrm{~mm} \times 5 \mathrm{div}]$
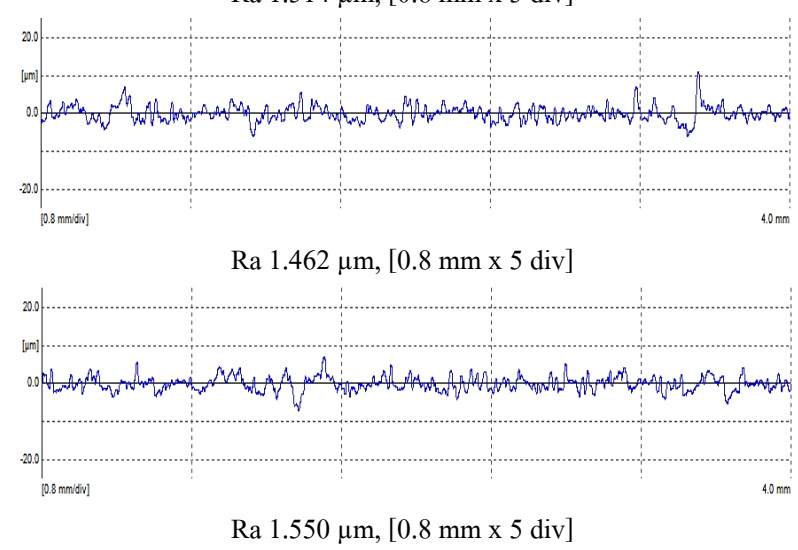

Figure3: The Comparison of Workpiece Surface Profiles EDMed with Different Electrode. 


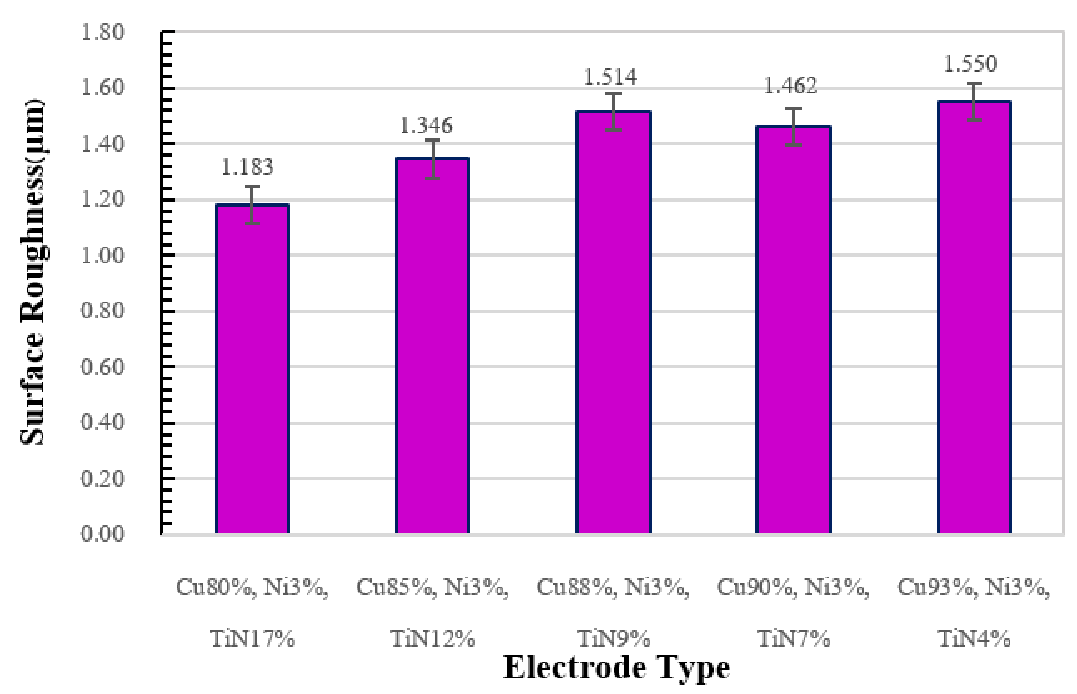

Figure 4: Surface Roughness of EDMed by Variation Cu-TiN.

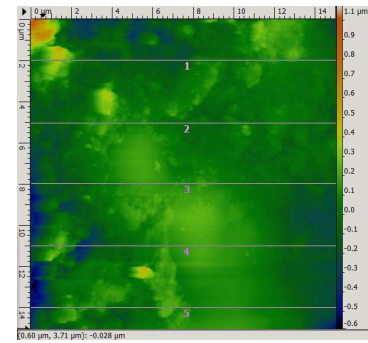

I-Measuring position

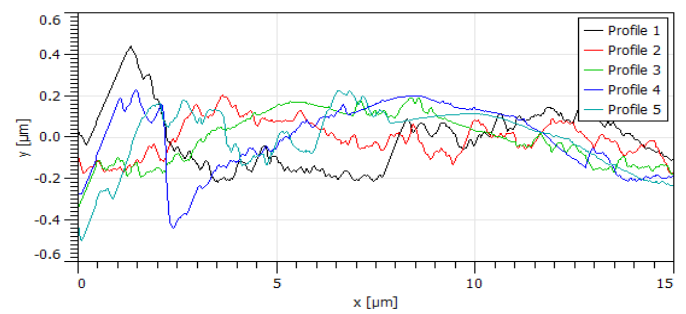

II-Surface Roughness from the Line Scanned Roughness

(a) The Best Surface Roughness of the Workpiece (WC-Co)

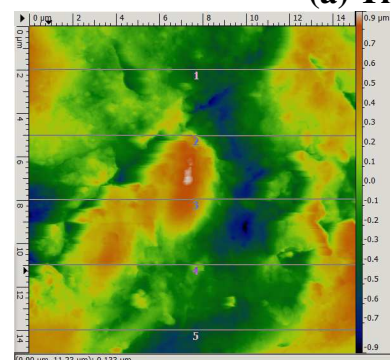

I-Measuring position

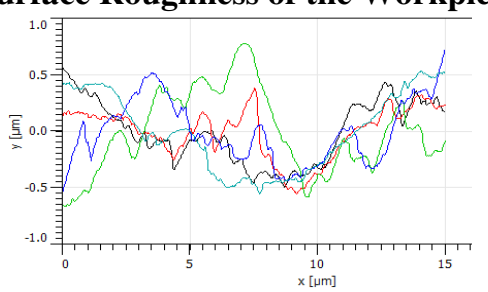

II-Surface Roughness from the Line Scanned Roughness

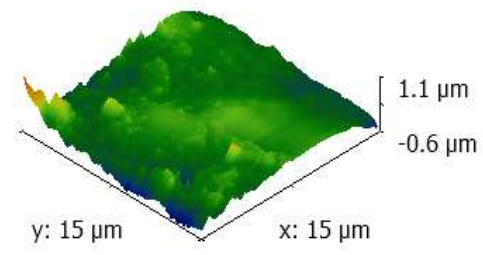

III-Surface roughness

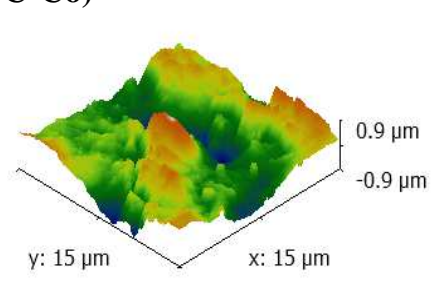

III-Surface roughness

b)The Roughest Surface Roughness of the Workpiece

Figure 5: Result of Surface Roughness Lowestand Highest Measuredan AFM

Figure 5 show surface quality of specimen (WC-Co) that is measured technique by atomic force microscopy (AFM) for the best and the roughest surface of workpiece, results found that the good quality surface or the lowest surface roughness had the low curve and quite smooth surface, noticing from the increasing graph at the positions shown in Figure 5 a) I-II and III which is surface roughness shows 3D of surface EDMed with electrode Cu80\%, Ni3\%, TiN17\%. Comparing to the highest roughness surface, which was very different, the surface was rough with deep large holes. Most surfaces were high and low differently as shown in Figure 5 b) which was the surface EDMed with electrode Cu93\%, Ni3\%, TiN4\%. This was the reason of the high surface roughness value [14-15]. This may cause the influence of the electrode and parameters used in sparking which is the main factor in the experiment. 


\subsection{Characteristic of Surface Workpiece and Electrode}

The study on Cu-TiN electrode compound affecting MRR, EWR and surface roughness average value and the test of sparking with tungsten carbide workpiece showed that composition ratio of copper-base electrode with low $\mathrm{Cu}$ and high TiN was the best electrode for EDMed. The evaluation of overall efficiency of surface quality after sparking with scanning electron microscope (SEM) indicated that electrode $\mathrm{Cu} 80 \%$, Ni3\%, TiN17\% provided the lowest roughness to the test workpiece as shown in Figure 6 a) (I). The surface was quite smooth with micro crack and pores all over the crack. The electrode surface from the inconsistent melt of surface had pores and bits all over the surface (Figure $6 \mathrm{~b}$ ) (II) and shows characteristic roughness from analysis of surface roughness using laser optical imaging techniques at position III.

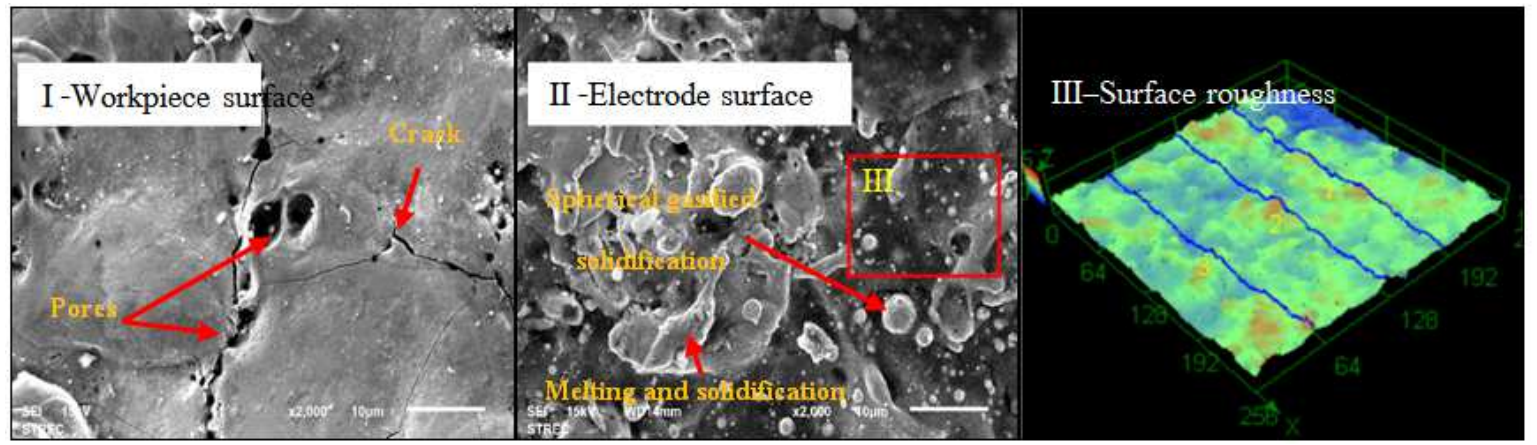

a)Electrode Surface Cu80\%, Ni3\%, TiN17\% (The Lowest Roughness)

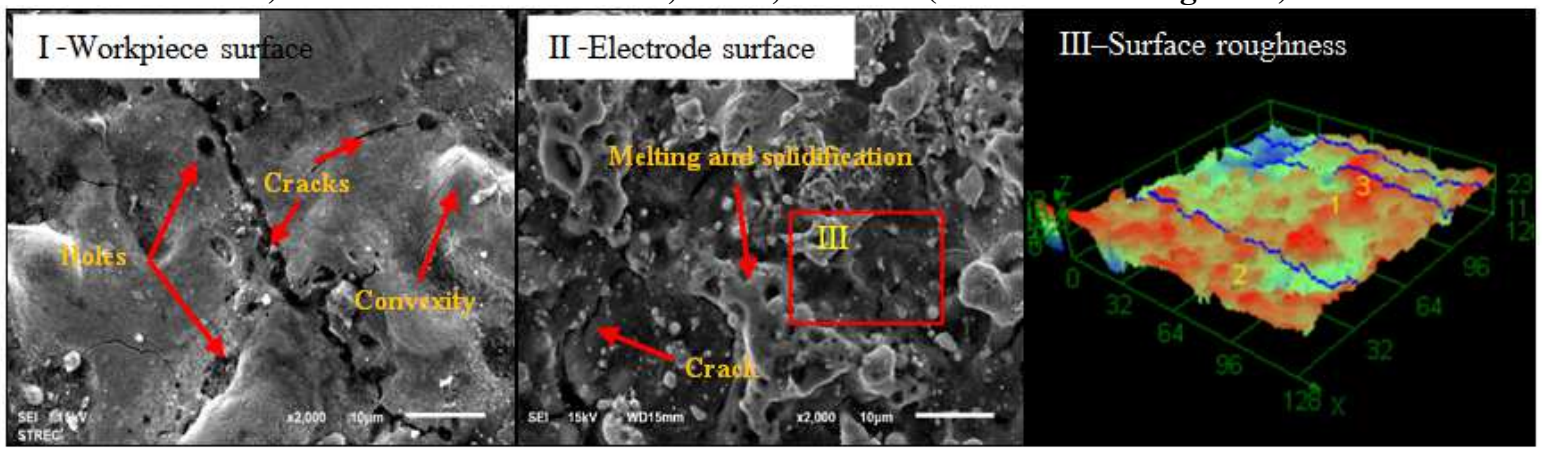

b)Electrode Surface Cu93\%, Ni3\%, TiN4\% (The Highest Roughness)

Figure 6: Characteristic of EDMed Surface Workpiece at Lowest and Highest Roughness.

Figure 6 showed the test workpiece surface that had the highest surface roughness. When sparking with electrode $\mathrm{Cu} 93 \%$, Ni3\%, TiN4\%, the surface had large crack with holes and pores and had higher convexity than the surface with low roughness as shown in Figure 6. Electrode had micro crack and the surface melted inconsistently which affected the rough surface according to the particles of each types of electrode as shown in Figure 6 b). Since the electricity used in the sparking process, which was the main factor of the EDM process, it affected the surface of test workpiece and electrode that had different composition rates of TiN, which was the particles that has higher melting temperature than the particles of other composition [16-17]. The occurrence of micro-cracking on surface workpiece (WC-Co)caused by factor used in the spark such as duty factor, voltage, current, polarity electrode, on/off time and other factors which causes crack with porosity on the specimen surface, therefore affect the surface roughness and surface roughness quality as mentioned above.

Table 5: Elements on Tungsten Carbide Surface

\begin{tabular}{|c|c|c|}
\hline Element & Weight (\%) & Atomic (\%) \\
\hline C & 25.53 & 81.64 \\
\hline Co & 5.51 & 3.59 \\
\hline
\end{tabular}




\begin{tabular}{|c|c|c|}
\hline $\mathrm{Cu}$ & 0.90 & 0.55 \\
\hline $\mathrm{W}$ & 68.06 & 14.22 \\
\hline Totals & $\mathbf{1 0 0 . 0 0}$ & $\mathbf{1 0 0 . 0 0}$ \\
\hline
\end{tabular}

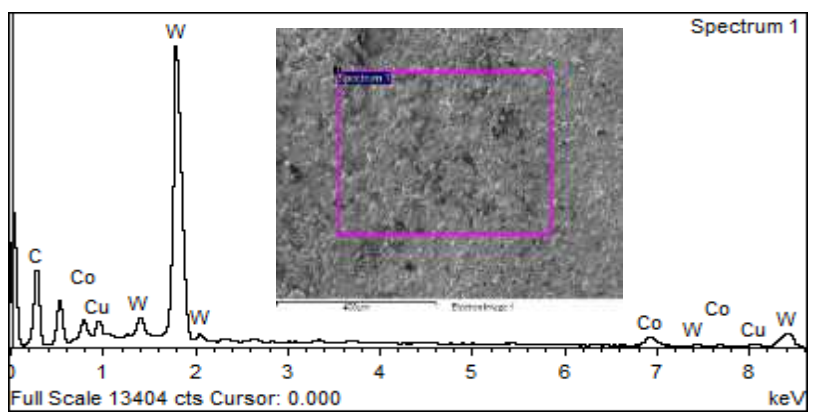

Figure 7: Analysis of Elements on Surface.

The analysis result on the element quantity on the test surface that had lowest surface roughness by sparking with electrode $\mathrm{Cu} 80 \%$, Ni3\%, TiN17\% applying energy dispersive spectrometer: EDS shown in Table 5 and the graph in Figure 7. Lots of element $\mathrm{C}$ were found covering the surface of test workpiece. This was because the particles of $\mathrm{C}$ was the result from the reaction between workpiece, electrode and dielectric from spark process. Moreover, there was $\mathrm{Cu}$ which was the compound of electrode came off to the surface of workpiece as it had low melting point, thus, it melted while sparking and came off on the surface of test workpiece [18].

\subsection{Characteristic Internal Structure and Electrode Section}

The study on $\mathrm{Cu}$-TiN electrode compound affecting to performance of EDM process consist of MRR, EWR and surface roughness average value and the test of sparking with tungsten carbide workpiece. Moreover, showed internal structure and electrode section at lowest and highest density, which is shown in Figure 8 and Figure 9, respectively.

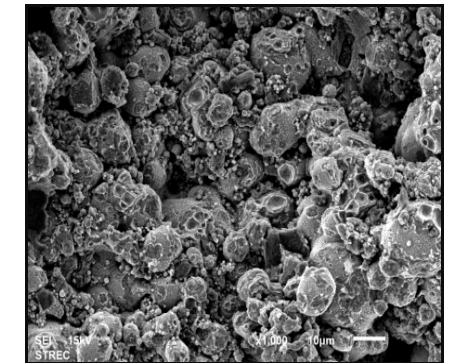

(I) Internal structure 3D

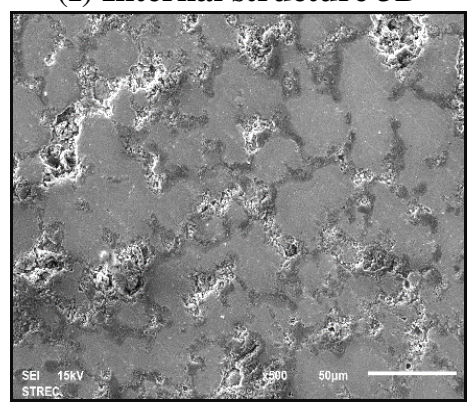

(II) Sectionelectrode

a) ElectrodeCu93\% Ni3\% TiCN4\% (Lowest)
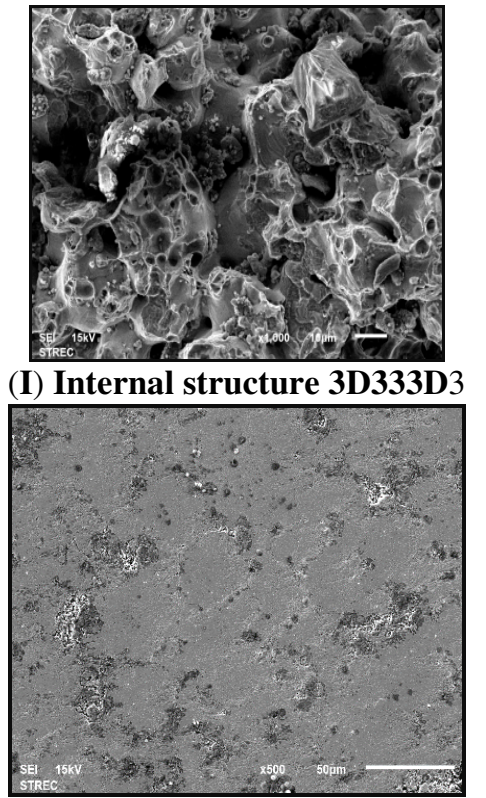

(II) Sectionelectrode o

b) ElectrodeCu80\% Ni3\% TiN17\%

(Highest)

Figure8: Characteristic Internal Structure and Electrode Section of Lowest and Highest Density 

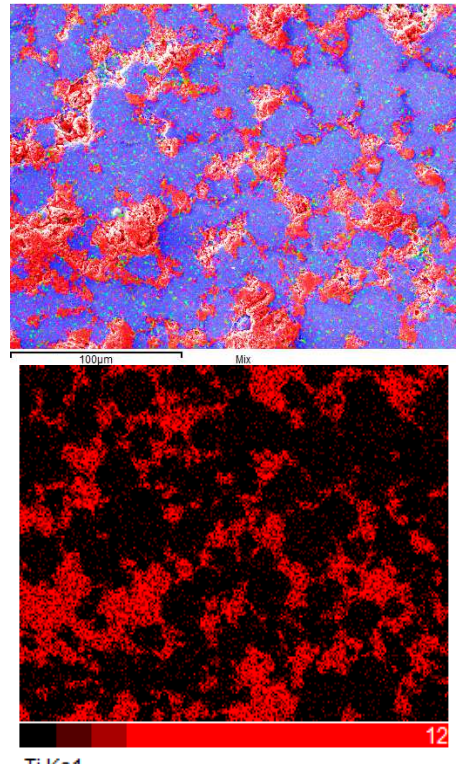

a) Electrode with the Lowest Density $(\mathrm{Cu} 93 \% \mathrm{Ni3} \% \mathrm{TiCN} 4 \%)$
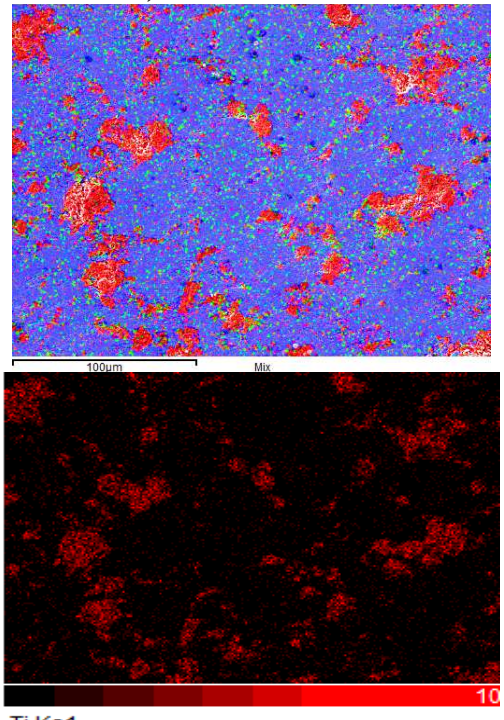

b) Electrode with the Highest Density (Cu80\%Ni3\% TiN17\%)
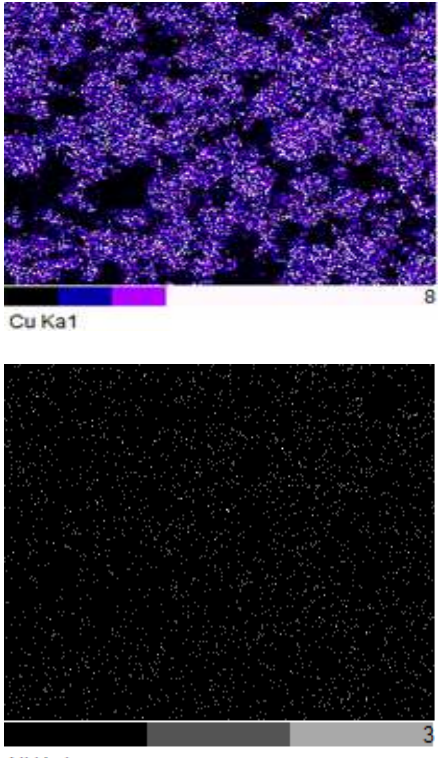

Ni Ka1
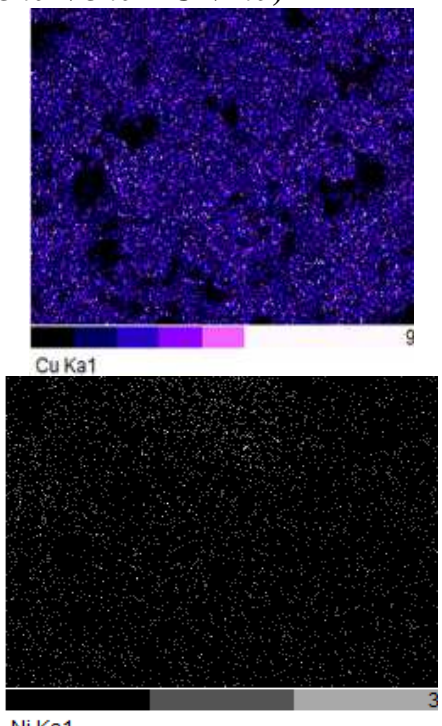

Nika1

Figure 9: Analyze the Distribution of Element using TechniqueEPMA-Mapping of Electrode

\section{CONCLUSIONS}

In this paper, the effect of compositions titanium nitride in copper-base electrode sintered during electrical discharge machining of tungsten carbide was studied. The experimental results can be concluded as follows.

- Electrode material composition at $\mathrm{Cu} 80 \%$, Ni3\%, TiN17\% had the highest MRR, $0.0038 \mathrm{~mm} 3 / \mathrm{min}$, the lowest EWR, $113.33 \%$ and the lowest surface roughness, $1.183 \mu \mathrm{m}$. Moreover, copper-based and TiN having good properties of thermal, electrical conductivity and improvement high melting point. These are influencing preferably to reduce EWR, and increase MRR. However, the low melting point of $\mathrm{Cu}$ increases the electrode wear ratio. 
- The surface of tungsten carbide had micro crack and pores all over the test workpiece of surface. The surface of electrode $\mathrm{Cu}$-TiN had bits that resulted from the inconsistent melt and a crack from the binding of particles in the electrode. For the surface of the test specimen and the surface of the electrode with different characteristics of flatness and roughness, which depends on the sparking efficiency of the materials used in the experiment from the analysis with AFM and laser optical imaging techniques.

- The surface of test workpiece sparked with electrode $\mathrm{Cu} 80 \%$, Ni3\%, TiN17\% had the particles of $\mathrm{C}$ and $\mathrm{Cu}$ on workpiece tungsten carbide surface, which is resulted from the reaction while sparking and distribution on area EDMed.

\section{ACKNOWLEDGEMENT}

The authors gratefully acknowledge the support of the Research Institute Development (RDI) of Rajamangala University of Technology Krungthep (RMUTK) and Kasetsart University (KU) for supporting equipment the research.

\section{REFERENCES}

1. H. C. Tsai, B. H. Yan, F. Y. Huang, EDM performance of $\mathrm{Cr} / \mathrm{Cu}$-based composite electrodes, International Journal of Machine Tool and Manufacture, 2003, vol.43, pp.245-252.

2. H. M. Zaw, J. Y. H. Fuh, A. Y. C Nee, L. Lu, Formation of a new EDM electrode material using sintering techniques, Journal of Material Processing Technology,1999, vol.89-90, pp.182-186.

3. N. Mohri, N. Saito, Y. Tsunekawa, Metal surface modification by electrical discharge machining with composite electrode, Annals of CIRP, 1993, vol.42, pp. 219-222.

4. A. Gangadhar, M. S Shunmugam, P. K. Philip, Surface modification in electro discharge processing with a powder compact tool electrode, Wear, 1991, vol.143, pp.45-55.

5. H. K. Kansal, Sehijpal Singh, Pradeep Kumar, Technology and research developments in powder mixed electric discharge machining (PMEDM), Journal of Materials Processing Technology, 2007, vol.184, pp. 32-41.

6. S. K. Ho, D. K. Aspinwall, W. Voice, Use of powder metallurgy (PM) compacted electrodes for electrical discharge surface alloying/modification of Ti-6Al-4V alloy". Journal of Materials Processing Technology, 2007, vol.191, pp.123-126.

7. Li Li, Y. S. Wong, J. Y. H. Fuh, L. Lu, EDM performance of TiCcopper-based sintered electrodes, Materials and Design, 2001, vol.22, pp. 669-678.

8. R. Ekachai, A. Dollatham, J. Pichai, Production of metal powders atomization technical, Journal of Engineering RMUTK, 2009, vol.1, pp.31-38.

9. Gaitonde V. N, Kamik S. R, Faustino M., Davim J. P, Machinability analysis in turning tungsten copper composite for application in EDM electrode, International Journal of Refractory Metal and Hard Materials, 2010, vol.28, pp.221-227.

10. V. Srivastava, P. M. Pandey, Study of ultrasonic assisted cryogenically cooled EDM process using sintered (Cu-TiC) tooltip, Journal of Manufacturing Processes, 2013, vol.15, pp. 158-166.

11. H. M. Zaw, J. Y. H. Fuh, A. Y. C. Nee, L. Lu, Formation of a new EDM electrode material using sintering techniques, Journal of Materials Processing Technology, 1999, vol.89-90, pp. 182-186.

12. H. C. Tsai, B. H. Yan, F. Y. Huang, EDM performance of $C r / C u$-based composite electrodes, International Journal of Machine Tools \& Manufacture, 2003, vol.43, pp. 245-252. 
13. Torres, C. J. Luis, I. Puertas, EDM machinability and surface roughness analysis of TiB2 using copper electrodes, Journal of Alloys and Compounds, 2017, vol.690, pp. 337-347.

14. E. Sireli, N. Orhon, G. Kl Sireli, Effects of wire-electro discharge machining process on surface integrity of WC-10Co alloy, International. Journal of Refractory Metals and Hard Materials, 2007, vol.64, pp.190-199.

15. M. P. Jahan, Y. S. Wong, M. Rahman, A study on the fine-finish die-sinking micro-EDM of tungsten carbide using different electrode materials, Journal of materials processing technology, 2009, vol.209, pp. 3956-3967.

16. Ho KH, Newman ST, State-of-the-art electrical discharge machining (EDM, International Journal of Machine Tools and Manufacture, 2003, vol.43, pp.1287-1300.

17. Mukherjee I, Ray PK, A review of optimization technique in metal cutting processes, Computer and Industrial Engineering, 2006, vol.50, pp.15-34.

18. F. Yerui, G. Yongfeng, L. Zongfeng, Experimental investigation of EDM parameters for TiC/Ni cermet,18th CIRP Conference on Electro Physical and Chemical Machining (ISEM XVIII), Procedia CIRP, 2016, vol.42, pp.18-22.

19. N. Maurya, K. Perumal l, T. Rahangdale \& N. Sanodiy, "Effect of Nanoparticles on Performance of Magneto-Rheological Fluids in Vibration Suppression”, International Journal of Mechanical Engineering (IJME), Vol. 7, Issue 5, pp. 1-10

20. Adel A. Omar, M. El-Shennawy \& M. Ayad, "Study of Wear Behavior of As Cast Tic/7075 Composite", International Journal of Mechanical Engineering (IJME), Vol. 4, Issue 4, pp. 45-52

21. M. El-Shennawy, A. I. Farahat, M. I. Masoud, \& A. I. Abdel-Aziz, "Heat treatment Effect on Micro alloyed Low Carbon Steel with Different Boron Content", International Journal of Mechanical Engineering (IJME), Vol. 5, Issue 4, pp. 9-20 
